\title{
A SYSTEMATIC SURVEY ON DIFFERENT MODELING METHODS TO MANAGE WAITING TIME IN AMBULATORY PATIENT SERVICES
}

\author{
Disha Chandra \\ Department of Mathematics \\ Mewar University, Chittorgarh, \\ Rajasthan, India
}

\author{
Dr Akhilesh Tiwari \\ Department of Management \\ Christ Institute of Management \\ Ghaziabad, Uttar Pradesh, India
}

\begin{abstract}
Hospitals experience frequent system block whenever or wherever there is more footfall than the expected number of patients. In order to manage this patient number, the hospitals have opted for numerous methods to cope up with these operational and structural problems in the hospital or any health care centre and improve patient's overall experience. The first step towards betterment in health services is to reduce the Outdoor patients' waiting time. This will improve the level of Patient satisfaction as well as overall efficiency of the system. For this purpose, several types of Operations Research Models have been developed in Health Care field. These models help in overcoming the waiting time issues faced by Outpatient in Hospitals that have been further discussed in the paper. Also, the use of electronic health records and practice management tools by Medical practitioners has enabled faster care and effective patient management. The goal is to provide relevant information to the Healthcare analysts engaged in enhancement of hospital efficiency through an appropriate OR model However, there is scope of further research in hospital system optimization for improved co-ordination between hospital departments, waiting time of patients queuing for special treatments.
\end{abstract}

Keywords - Waiting Time, Outpatient, Queues, Healthcare

\section{INTRODUCTION}

With the increasing demand of healthcare services, the patients waiting in a queue is a significant problem faced by our healthcare system. The government health services have limited system capacity due to which this problem is severe there. Private health care system is trying to fulfil the increasing population needs. Due to the ever growing demand of better health services, the system is facing problem of waiting lines. Overcrowding and congestion in the healthcare system are few major problems, if not dealt effectively, could lead to huge loss to human life (Chandra, 2017).
The patients consider comprehensive health care service as more suitable and desirable for treatment, as it provides prompt treatment and minimizes the time for availing a health service with an emphasis on the favourable treatment (Dansky \& Miles, 1997) [1]. Vissers et. al. (1998) emphasized that the patients who need an overall support or who wish to get services at single place to save on time and resources come to such comprehensive centers as there is collective availability of doctors. This leads to excessive pressure on the system overall which results in the formation of queues. Changes and major challenges in the health sector have led to the changes in the outpatient services[2a]. Mardiah \& Basri et al. (2013) asserted that effectively managing patient flow in an outpatient unit is a key to achieve operational excellence as well as ensuring clinical quality [3]. That's essentially true for an outpatient department in a large hospital as it handles very large volume of patients with a diverse case mix. The basic characteristics of healthcare services, just like financial services, supermarkets or barbershops, include waiting lines or queues which cannot be avoided (Zeithaml, Parasuraman \& Berry, 1985) [4].

Dinesh et.al. (2013) stated that patients' waiting time has been defined as "the length of time from when the patient entered the outpatient clinic to the time the patient actually leaves the OPD"[5]. Dansky (1997) presented several definitions of waiting time [1]. Leddy et. al. (2003) referred waiting time as the total time that a patient spends to receive a particular service after entering the hospital till entering the examination room to visit a doctor [6]. Sharif et. al. (2003) defined waiting time as the total time from registration until patient consults a doctor. There are two waiting times, the first is time taken to see a doctor and the second is time to obtain medicine [7]. Registration time including the time for payment process and patient's record entry also forms part of patient's waiting time. This aspect of waiting time can be dealt with the new techniques of reducing waiting time. The other aspect i.e. waiting within the hospital can be reduced only through basic interventions approaches including deploying appropriate 


\section{International Journal of Engineering Applied Sciences and Technology, 2019 Vol. 4, Issue 1, ISSN No. 2455-2143, Pages 14-23 \\ Published Online May 2019 in IJEAST (http://www.ijeast.com)}

work force including doctors, staff etc. (Johannessen and Alexandersen, 2018) [8].

A study revealed that the average wait time in American hospital emergency rooms is approximately 4 hours, which reflects the intolerably low value and service in a hospital. In a patient satisfaction survey conducted by Maritz, Hodkinson and Wallis et. al. (2010), Ernst \& Young (2010), Lindsay, Schull and Bronskill et. al. (2002) established that waiting time had scored worst among all key quality indicators measured in the study. Most of the respondents who had received medical care in any hospital indicated that they have been disappointed due to long waiting hours [9-11].

Boudreaux et. al. (2004) explained that during the Federal Throne Speech, it was stated by the British government that the length of waiting times for the most important medical processes is a litmus test of the health care system. Therefore, appropriate steps were mandated to be taken to reduce waiting time in hospitals as a quality improvement measure in Health care centers. As a Quality improvement practice, hospitals had to manage the waiting time through a process based on management to ensure patient satisfaction[12].

Pandit and Kulkarni, et. al. (2018) in their work emphasised that effectively managing the patient flow in an outpatient unit is a key to achieve operational excellence as well as ensuring clinical quality[13]. Outpatient department in a large hospital handles very large volume of patients with a diverse case mix (Mardiah \& Basri, et. al. 2013) [3]. Bajpai et al. (2014) in his research work claimed that waiting is a consequence of the mismatch between the available hospital resources and the needs for care[14]. This mismatch is generally attributed to having insufficient resources to meet demand for health care. However, other reasons like lack of planning, coordination, communication in delivering health care services are also responsible for this unsynchronized system (Vargas et al. 2016) [15].

This paper surveys such type of issues which have lead to increased waiting time faced by Out Door patients. Various types of Operation Research Models have been applied to deal with the problem of waiting time in the Health Care sector. Some of them have been discussed in the next section.

\section{CHALLENGES FACED IN OUTPATIENTS DEPARTMENT}

\subsection{Patient Flow:}

With the increasing population and furthermore older population, the no. of patients has been growing exponentially.

Koo et al. (2010) found patient flow is a major element in improving efficiency in the delivery of healthcare services. Majorly patient flow requires addressing three aspects of an outpatient unit: arrival of patients, service process, and queuing process. It must be noted that the patient's arrival system includes controlling patient group size, balancing patient volume across available sessions and achieving desirable patient arrival pattern within a session. Missing out the management of even a single of these hinders the whole process of effective patient management[16].

Hospitals essentially operate as a collection of independent departments that compete for restricted resources. The coordination of processes within the patient flow is difficult to achieve. Melo et. al. (2012) found that in a high-cost unit such as the operating theatre, schedules for elective surgeries are usually created without analyzing their effect on other hospital departments such as diagnostic units (e.g. medical imaging and laboratories), nursing wards, and recovery rooms. The lack of dexterity results in the underutilization of expensive resources (staff and equipment) and in delays in the patient flow. Moreover, it contributes to increased patient inconvenience due to longer waiting times[17].

It came to light that a Children's Hospital in Miami faced a similar problem when it experienced an increase in patient volume, escalating the scheduled monthly visits to 4,800 patients. In addition, the hospital experienced an unscheduled volume of 1,900 patients per month. This added volume drove up wait and discharge times, negatively impacting satisfaction levels and, most importantly, patient care. One of the key issues faced by the hospital included High patient wait times particularly in the areas of triage, admissions, data entry and insurance verification[18].

\subsection{Admission System:}

In most hospitals, appointment systems are used to schedule patient appointments for consultation with the doctor or any medical examinations.

The process of assigning time slots for serving out and inpatients arises in diagnostic and treatment units that deals with uncertain service times, no-shows, cancelations, and walk-ins. Melo(2012) said that a good appointment schedule ensures shorter patient waiting times and lesser staff overtime considering the patient load and the resources like staff, rooms, and equipment available at a given time. Commonly used approaches fall into four categories: mathematical programming (deterministic and stochastic), heuristics, queuing theory, and simulation[17].

Brahimi \& Worthington et. al. (1991) in their research work confirmed that the basic problem in appointment systems is stress which is laid on minimising the idle time of the doctor and not on patients waiting time, wherein the two parameters are equally important to mark an efficient appointment system [19]. This problem was first tackled by researchers such as 


\section{International Journal of Engineering Applied Sciences and Technology, 2019 \\ Vol. 4, Issue 1, ISSN No. 2455-2143, Pages 14-23 \\ Published Online May 2019 in IJEAST (http://www.ijeast.com)}

Bailey et. al. (1954), Jackson et. al. (1954) and by Vissers et. al. (1998). Any patient who schedules an appointment faces two types of delays. Virtual delay is time between request of appointment and actual appointment schedule. Other is, after arrival for the scheduled appointment caused due to Emergency cases or unscheduled patients. This direct waiting time is the greatest source of dissatisfaction[2,4,20].

The consequences of waiting are clear from the news revelation about the Veterans Affairs Health Care system in US where around 40 U.S. veterans died due to lack or delay in getting appointment in a Veterans Hospital (https://edition.cnn.com/2014/04/23/health/veterans-dyinghealth-care-delays/index.html)

The admission system has been developed for hospitals with features to be information ready for better decision making.

\subsection{Retrieval of Patient Information:}

The area of information technology has focused to the development of modern hospital information systems (HIS). These systems have been designed to deal with all aspects of information processing in a hospital which enable the collection, storage, management, and retrieval of data related to the all aspects of providing services within the hospital starting from clinical, financial and administrative. However, the use of relevant resulting surplus information to make correct decisions has received much less attention. Most HIS lack planning tools to support decision making.

Aghazadeh, Aliyev and Ebrahimnezhad et. al. (2012) said that Hospital Information System (HIS) helps in supporting hospital activities at strategic, practical and Tactical level. In other words, goal of hospital information system (HIS) is using of computers and communications equipment for collecting, storing, processing, readout, and communication between patients cares with administrative data on all hospital activities and comply needs of all consumers system. In academic hospitals research and training support is also one of the hospital information system (HIS) goals[21].

Choudhury et. al. (2016) developed a HIS, Sushrut, with the objective of streamlining the treatment flow of a patient in the hospital, while allowing doctors and other staff to perform to their peak ability, in an optimized and efficient manner [22].

It helps proper flow of patient information within different Departments at all levels and care of patient with a PC: using of the appropriate Work station, physician can access patients and hospitals easily from your location or where he/she is present. Better patient management and follow ups can be done better in these systems. Therefore, access to patient history will be better and faster. Some of the reasons to use a HIS are Data Presentation, ease in taking appointment in
Hospitals, better communication of information and decrease the time and errors. Main features of these systems will be their vast capacity in collecting, recording and retrieving information that will provide monitoring the patient. Patient data keeps on being added at each level where the patient is directed, be it a doctor or examination reports [22].

\subsection{Examination process:}

Melo et. al. (2012) mentioned that auxiliary services such as those provided by logistics seem simple and straightforward and hospitals do not really consider them as part of their core processes. However, they impact significantly on the quality of health care provided and on hospital costs. For instance, late delivery of an inpatient to a diagnostic department due to a late booking of the request for transport disrupts the planned schedule of the department and results in reduced patient satisfaction. Often, a new appointment time is set, thus rendering patient waiting time inevitable [23].

In 2011, Monthly Performance Report of National Health Service(NHS) revealed in United Kingdom that the number of patients waiting for diagnostic tests such as ultrasound or XRay, has been growing every year, where 6 weeks has been the recommended waiting time for some diagnostic tests, which included detecting terminal diseases as well. (http://www.theguardian.com/society/2011/oct/05/nhswaiting-times-increase-tests)

Also, Melo et. al. (2012) said that it is a common practice to assign same appointment time to several inpatients as a means to avoid idle time in case of patient no-show or tardiness. The latter aspect was a consequence of lack of coordination with the patient transport service for bringing inpatients to the radiology department and escorting them back to their nursing wards [23].

\subsection{Emergency cases:}

The researchers, Fiems, Koole and Nain et. al. (2005) explained that patients are usually scheduled at equal intervals and that each patient requires a fixed duration of examination time. However, emergency requests interrupt a patient's examination and the latter has to start it all over after such an interruption. It varies from seeing the doctor first in the tradeoff between emergency and outdoor patient or a doctor could be using the equipments for carrying out medical examination where they may be shared with the emergency department. The equipment is readily made available for emergency cases interrupting the examination of scheduled patient. When all emergency examinations are carried out, then the interrupted process could be reinstated [24].

Fiems, Koole and Nain et. al. (2007) investigated the effect of emergency requests on the waiting times of scheduled patients 


\section{International Journal of Engineering Applied Sciences and Technology, 2019 \\ Vol. 4, Issue 1, ISSN No. 2455-2143, Pages 14-23 \\ Published Online May 2019 in IJEAST (http://www.ijeast.com)}

by determining the processing times. In this anticipatory repeat priority queuing system, the scheduled patients were interrupted by the emergency patients and the service restarted for the scheduled patients as opposed to being resumed after the service of emergency patient. This paper modelled a single server queue and divided time into equally long slots. Emergency interruptions were considered to have no vacant time i.e. no server available from the point of view of the scheduled patients resulting in a discrete-time queuing model with exhaustive vacant times.[25]

Koeleman and Koole et. al. (2012) found the optimal arrival times for a combination of patient waiting time, doctor idle time and tardiness. He presented a model for finding optimal appointment schedule in a hospital with frequent emergency arrival interrupting the scheduled patients, using local search algorithm [26].

Major challenges faced by hospitals over the years have led to development of plethora of management techniques which range from implementing queuing models, installing scheduling software to application of Six Sigma approach to deal with the increasing waiting time of Outpatients.

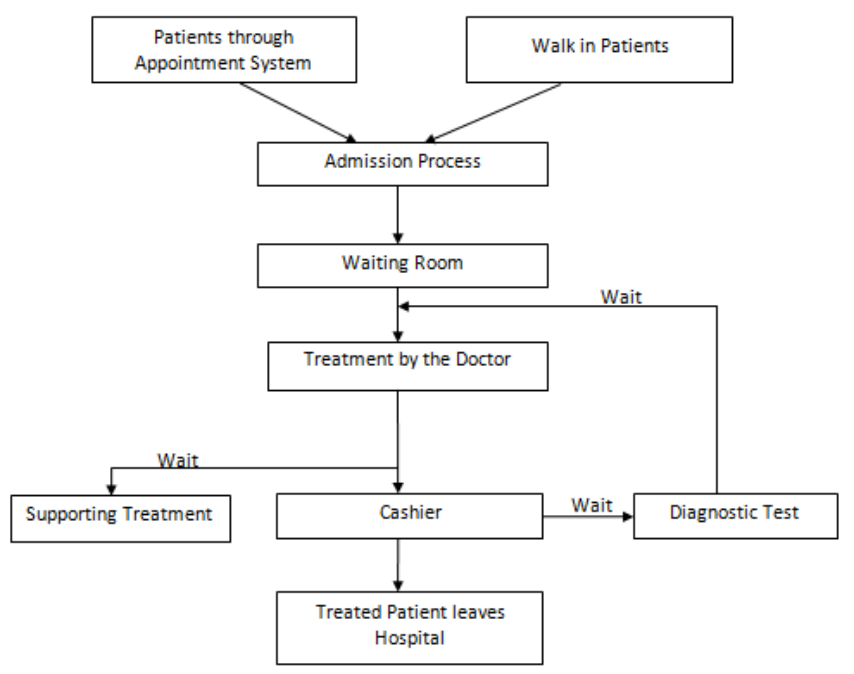

Fig(1): Flow Chart of Outpatient visiting a Hospital

\section{CHARACTERISTICS OF A SERVICE SYSTEM}

The researcher Chowdhury et.. al. (2013) stated that any service process must be observed for following main characteristics for deciding the best suitable system for itself, a) Arrival patterns i.e. the system inputs (referred to as calling population), b) the queue and (c) the service being provided [27].

\subsection{Arrival Pattern}

For understanding the Arrival Patterns of the inputs of any service system or patients in case of hospitals has three major characteristics, size of the calling population, the pattern of arrivals and the behavior of the arrivals.

\subsubsection{Size of the Calling Population}

The population size could be either unlimited (considered as infinite) or limited (considered as finite).

When the number of arrivals at a given moment is small number of potential arrivals, the calling population is considered to be unlimited. Most queuing models assume the infinite calling population. Else, the system modeling becomes much complex. The small potential no. of patients arriving at a hospital is considered as infinite calling population. However, calling population will be considered as finite if a service with only eight machines faces service breakdown and requires the service of machines.

\subsubsection{Pattern of arrivals at the system}

There is some schedule or way in which the Customers or patients or machines would arrive in any service facility or they could even arrive randomly.

Chowdhury et. al. (2013) stated that the patient arrivals are considered random when the incidence is independent in each case of arrival and the occurrence of arrivals cannot be predicted prior. Generally arrivals are estimated through patterns, the number of arrivals per unit of time, estimating the arrivals as a probability distribution known as the Poisson distribution [27].

\subsubsection{Behavior of the Arrival}

The arrivals, people or machines, come for being served and wait in the line forming a queue until they are served. Yet, it has been noted that arrivals have been switching or leaving the queue also, as per the availability of time with them or impatience, known as balking or reneging. Reneging refers to those who enter the queue but due to impatience leave the queue. This is often seen in a super market with long queue and customers in the queue leave the queue due to impatience or change their queue to a smaller queue length. This calls for most important service level decisions by the managers to render better services.

Balking refers to customers who refuse to join the waiting lines because it is to suit their needs or interests.

\subsection{Waiting Line characteristics}

Length of a waiting line or queue can be either limited or unlimited. A queue is limited when it cannot increase to an 


\section{International Journal of Engineering Applied Sciences and Technology, 2019 \\ Vol. 4, Issue 1, ISSN No. 2455-2143, Pages 14-23 \\ Published Online May 2019 in IJEAST (http://www.ijeast.com)}

infinite length. A queue is unlimited when its size is unrestricted, as in the case of the hospitals.

\subsubsection{Queue discipline}

Another characteristic of the queue is queue discipline i.e. the rule by which patients or queue members are to receive service. Most systems use a queue discipline known as the first in, first out or priority based rule (FIFO). This is as per the service systems, those dealing with emergencies or not.

\subsection{Service Facility Characteristics}

The service facility has two basic properties, configuration of the service system and the pattern of service times.

\subsubsection{Basic Queuing System Configurations:}

The main classification of the Service systems is done in terms of their number of channels or servers, and number of phases or service stops, that must be made.

The term FIFS, i.e. first in, first served is one commonly used service system. Another discipline, LIFS (last in, first served), is also common in systems where the material is stacked or piled. In such case, items at the top are served first in such configuration.

A single-channel system, with one server or, multi-channel system with multiple servers is configured as per the nature of service. Many banks, hospitals, airline ticket counters or any even barbershops are multi-channel service systems.

A single-phase system is where the customer receives service at only one station and then leaves the system. Multiphase system has two or more stoppages before the system exit.

\subsubsection{Service Time Distribution:}

Service patterns can be either constant or random. If service time is constant, it serves each customer for same time duration. However, mostly service times are of random duration and are described as following negative exponential probability distribution (Chowdhury, 2013).

Further different types of models used by hospitals to minimise outpatient waiting time, have been discussed.

\section{TYPES OF MODELS USED IN OUTPATIENT DEPARTMENT}

\subsection{FIFS Model (first in first serve)}

This technique is known as the queue priority and is also compared with the queue of getting food. This model can be applied to the cash department and examination room in hospitals. FIFS technique is another approach used for the analysis of the waiting time of the outpatients and how to reduce it. In hospitals, a low priority patient admitted first could be the last person who gets out of the admission queue in case a patient with higher priority arrives. The patient admitted first shall be the last person exiting from the examination room in case of emergency departments [27].

However, Ozturk et al.(2010) said that this technique is used in the entire process from pre-admission till the exit of the patient from the examination room. This happens due to the priority levels of the patients in different departments. When we apply FIFS model in the Emergency department of a hospital, the primary care patients get delayed as there is a priority discipline for different category of patients in it [28].

Helbig et al.(2007) established that sometimes the specific Time duration for each low priority patient's visit by doctor is as short as 5 minutes which should be at least 15 minutes for each patient. Perhaps one of the reasons behind the frequent visits of patient to the clinic is the shorter time duration which is spent on them. In addition to it, this duration of time indirectly increases the waiting time of the patients. To manage the waiting patients, hospitals maintain the pleasant ambience in them [29].

\subsection{Admission Model}

In admission model, a patient should not have any wait time at all before admission. A reservation system that functions in two ways helps in implementing this method. In one way, patient admission is done through telephone. In this method, the patient contacts the hospital by phone and provides basic information to reception and gets admission into the queue, thus approaching the hospital at a given time. Another reservation system is through the computer, wherein the patients enter their basic information in the website of the hospital and get an appointment scheduled, thus entering the virtual queue and reaching at the time of scheduled appointment.

Software for taking hospital appointments have been developed so far in areas like E-commerce, m-commerce etc. The internet initially revolutionized communication and access to information; however, in more recent times there have been rapid improvements in mobile technology that has further expanded the communicative abilities of individuals and businesses alike. Mobile technologies and use of the internet have given us a new frontier of information distribution. Edward and Suresh (2009) developed a system for health care services for searching and scheduling an appointment using a J2Me mobile handset [30]. 


\section{International Journal of Engineering Applied Sciences and Technology, 2019 \\ Vol. 4, Issue 1, ISSN No. 2455-2143, Pages 14-23 \\ Published Online May 2019 in IJEAST (http://www.ijeast.com)}

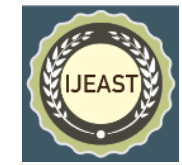

Hylton and Sankaranarayanan et. al. (2012) developed an intelligent agent based system using android which was 1 st of its kind of research. It is a software which can be accessed in mobile environment for fixing appointments in respect of health applications by applying mobile agents (software) which would replicate the job of the human being as it has the ability to sense an environment that it is located in, then carries out some action, based on the information / data that it gathers from that environment and schedules the appointment based on the level of priority of the patient [31].

Wenjun Cao et. al(2011) showed that in a China hospital, patient appointments were booked through the general Queuing system of appointment and a Web based appointment system, but in both cases, a major difference appeared in the degree of patient satisfaction, total waiting time etc. It was noted that the outpatients have not been using the Web based appointment scheduling system rather than traditional methods. Reasons for not using the online appointment system were ignorance, not trusting the internet, inability to use a computer. However, using the Web based appointment system instead of the usual queuing method could significantly increase the patient satisfaction level and reduce the total waiting time effectively [32].

\subsection{Queuing Theory}

This model is used when the number of outpatients is very large. Helbig et al. (2007) analyzed and suggested that there should be an increase in the patient admission booths and an increase in the number of examination rooms. Also, adequate human and physical resources should be present. This model is used in learning hospitals mostly [29].

Researchers such as Bailey et al. (1954) and Vissers et. al. (1998) used this approach of formulating the problem as a Queuing system when there is a large no. of patients waiting in Queue and Jackson et. al. (1957) used queuing theory and simulation to put the system in place, by developing queuing networks dealing specifically in open queuing networks $[2,4$, 33].

Afrane and Appah et. al. (2014) applied Queuing Theory and modelling to a queuing problem in out-patient department of a hospital in Ghana using a descriptive, observational and expost facto method of collecting data and modelled five types of Scenarios for different Server Capacities of its Out-patient department, compared their capacity utilization, average number of patients in queue and in the system, average waiting time of patients in the system using a software. Thereafter, using Queuing theory and Modelling as a tool in Decision Making, he proposed a minimum specified no. of doctors to be available and a user friendly computerized database system in the hospital for optimal performance of the system [34].
Adeleke, Ogunwale and Halid et. at. (2009), studied queuing problems encountered at a University based Health centre, considering the waiting of patients in such university health centers as a single-channel queuing system with Poisson arrivals and exponential service rate where arrivals are handled on a first come first serve basis. It was discovered during the study that the traffic intensity i.e. the probability of patient queuing on arrival was high. Which clearly indicated that there is a higher possibility that the patient would wait for treatment as the doctor is busy examining the patient who arrived earlier. Hence, they proposed $\mathrm{m} / \mathrm{m} / 1$ queuing system for such set ups and availability of more doctors and paramedical staff [2b].

Queuing models have a big advantage that a complex queuing situation is changed into a simple mathematical equation, which help in getting an optimal solution to reduce the waiting time. However, it needs to make irrational assumptions sometimes like person does not enters the queue at all as there are too many people already queued up. Also, if the analytic does not have enough background of Operation research, he/she might apply a wrong queuing model due to extensive nature of such models practically.

\subsection{Electronic Visit System}

Taylor et. al. (2006) said that electronic visit through the web network is the best present system to reduce the waiting time in hospitals and clinics. This model is obtained from the doctor's consultant and patient's relationship. These models are mostly used in hospitals and private clinics. The overhead costs of clinics have also been reduced by using these systems. Lack of patient, physician and consultant relationship in the emotional level has been a limitation of this system though. Such systems are mostly used in specialties such as psychiatry, where the doctor and patient meet only if it is necessary at times. The experts promote use of this system for family physician and the specialist relationship. This system is expanded and works on the patient, family physician and specialist. This system works quiet well in the developing countries and particularly in the developed countries where medical information systems and new applications are more advanced and extensive [35].

Mohebbifar et. al. (2013) established that in waiting time for the outpatients of ophthalmology clinic with an average of 245 minutes for each patient allocated the maximum time among the other clinics for itself. The Orthopaedic clinic had the minimal waiting time including an average of 77 minutes per patient. The total average waiting time for each patient in the educational hospitals under this study was about 161 minutes. And by applying some models, we can reduce the waiting time especially in the realm of time and space before the admission to the examination room [36]. 


\section{International Journal of Engineering Applied Sciences and Technology, 2019 Vol. 4, Issue 1, ISSN No. 2455-2143, Pages 14-23 \\ Published Online May 2019 in IJEAST (http://www.ijeast.com)}

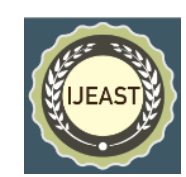

In Mayo Clinic Health System in Iowa, an e-health system known as Mayo Clinic Care Network or MCCN has been developed, wherein patients, their physicians and specialists of Mayo Clinic are connected at different levels ensuring integrated clinical practice. It consists of like-minded organizations that share a common commitment to improving the delivery of healthcare through high quality medical care. It ensures quick and convenient access to the expertise of Mayo Clinic so that patients can benefit without having to travel to a Mayo Clinic facility[31].

MCCN's tools and services include AskMayoExpert, eConsults and eTumour, in which AskMayoExpert is a database for medical professionals who wish to gather essential answers to clinical questions with supporting information and key facts. It also offers concise information on how to manage a disease, patient care guidelines, treatment recommendations and reference reading materials for a wide variety of medical conditions. eConsults is a platform to connect the physician to specialists of Mayo Clinic for inputs on any specific question. By accessing the knowledge and expertise of Mayo Clinic, family physicians can improve locally provided care and keep their patients closer to home, avoiding unnecessary travel. eTumor board conferences for multidisciplinary review and informal advice [37].

Another such service is Medeo, used in British Colombia to electronically visit their physician through videoconferencing and also allows the physician to keep and share the medical records including photographs for further consultation. It offers doctors with the same services that clinics do, including appointment scheduling, billing, and record storage. Medeo is intended to connect patients with their current primary care physician/s if they sign up for the service [38].

\subsection{Process Model}

Willcox et al.(2007) said that process models are the best for identifying and solving the problems of outpatient waiting time in the hospitals. This model presents that the complete process should be examined to identify the problem in system [39].

Based on this, a management philosophy known as "Lean" was coined way back in 1988, which used the principles of Toyota Production System (TPS) that is focussed at improving upon the quality or value and eliminate the wastage. This process-improvement methodology and management improvement system has been used in many US hospitals to streamline their daily processes, improve upon finances, employee satisfaction and the most important factor, enhancement in patient care. It is directly acting on elimination of waste. In terms of Lean, wastage is related to time and motion. However, researchers, Čiarnienè and
Vienažindienè(2012) state that there is no wastage of time and motion in this methodology which means increased productivity, efficiency, employee satisfaction, and patient satisfaction. Lean optimizes the clinical processes cutting out the unnecessarily wasted time due to mashed up clinical activities and needless motion [40].

Mohebbifar et al.(2013) conducted a research in educational and learning hospitals in Iran and found that $7.53 \%$ waiting time was found to be related to the distance between the cash counters and the examination room and the patient's reception from the outpatient's reception till the entry into the examination room, The study suggested that the factors having more effect on this process should be considered more than other factors and the long term processes should be reduced or eliminated. For this purpose, acceptance model can be used before the admission. For Example, patients can be admitted by accepting the patients through simulation model. Also, in learning hospitals, the faculty physicians are mostly specialist and should begin counselling immediately after the admission of the first patient. It lead to greater utilization of time and they will get more time to examine the patient[36].

This model brings the system to optimal utilization of the resources available but it could be very difficult to do due to behavioural concerns of the people undergoing procedural change, as they may be aware or unaware of the need to change but display no interest in learning how to change as they are not considering change[39].

\subsection{Simulation}

Simulations reproduce the behaviour of system under all types of operational conditions. With the help of simulation models, certain system variables are manipulated to determine their effect on the system and draw conclusions about how the system could work in the most efficient manner. It acts as a decision making tool needed to plan in the most complex and dynamic healthcare systems.

Salleh, Yusop and Ali found that the outpatients flow is congested due to unbalance between the number of outpatients and the availability of doctors at a time in Jitra Health Centre of Kedah. So, simulation model of outpatient flow was established to determine the bottlenecks for outpatients arriving at the centre [41].

Aeenparast et. al.(2013) designed a simulation model for predicting the changes occurring in outpatient waiting time due to changes in system. The model used the data of arrival times, service times and flow of 357 patients in a learning hospital in Tehran. He analyzed 10 scenarios of changing patients admission time and changing doctor's work time with the help of this simulation model which was created using AweSim, a general purpose simulation system that uses 


\section{International Journal of Engineering Applied Sciences and Technology, 2019 \\ Vol. 4, Issue 1, ISSN No. 2455-2143, Pages 14-23 \\ Published Online May 2019 in IJEAST (http://www.ijeast.com)}

Windows technology. The scenario that reduced the outpatient waiting time by $73.4 \%$ was finally chosen [42].

This model helps us in experiencing the grim situations that a system could face and find ways well in time to tackle such issues. However, a major disadvantage of this system is their cost and ease in using it, as some simulation programs lack enough flexibility for desired analysis [42].

\subsection{Miscellaneous Approach}

Another widely used method for reducing waiting time of Outpatients has been taking Six Sigma approach by Hospitals.

It came to light that a Children's Hospital in Miami faced a similar problem when it experienced an increase in patient volume, escalating the scheduled monthly visits to 4,800 patients. In addition, the hospital experienced an unscheduled volume of 1,900 patients per month. This added volume, drove up wait and discharge times, negatively impacting satisfaction levels and, most importantly, patient care. One of the key issues faced by the hospital included: High waiting times of patients, particularly in the areas of categorisation, admissions, data entry and insurance verification [43].

Understanding the need for patient satisfaction, the hospital approached Genpact to analyze their current hospital operations and identify areas for improvement. Genpact applied the Lean (a process model), Six Sigma and Smart Enterprise Processes (SEPSM) methodologies, particularly meant for business processes, to core hospital functions with the goal of improving hospital efficiency and enhancing the patient experience and levels of care. It resulted in better patient inflow and a more intelligent enterprise. Result of Genpact's innovative solution quadrupled the return on investment for the hospital through optimal utilization of equipments and infrastructure ensuring additional capacity, $18 \%$ decrease in patient wait times and $3 \%$ increase in customer satisfaction [18].

Dinesh et al. (2013) conducted a study in a university hospital in India, outpatients waiting time reduced significantly when DMAIC method under Six Sigma technique was applied to its cardiology department. Based on the analysis some improvements were suggested in the existing system such as increasing registration counters, appointing usherers for guiding patients, additional staff for taking telephone calls and imparted training of call attending mannerisms and conducting Voice of Customer (VOC) survey to get a reflection of patients expectations, which led to reduced waiting time and superior patient satisfaction (Dinesh et al, 2013). However, effective implementation of Six Sigma methodology is a concern as there is no proper guideline on how to do it [5].
Medical practitioners have also been opting for electronic health records and practice management tools to enable faster and more effective care to the patients and also saving their valuable time and money. Few examples of Electronic Health Record system have been discussed below:

Electronic Health Record: With an Electronic Health Record (EHR), a patient's record is electronically maintained, which follows him everywhere, starting from the family doctor to a specialist physician to hospital and to any place from where he receives health services. And, he and his doctors can access all of this information and communicate with a smartphone or computer.

PedsConnect: It is a fully integrated paediatric electronic health record (EHR) and practice management system. It enables the paediatricians and other healthcare providers to efficiently access and share clinical patient data at all required points such as specialist doctor, hospital. It helps ensure that every child receives the most effective and immediate care. PedsConnect offers a full range of practice management tools that save valuable time and money of the doctor and patients both.

In Canada, Sunnybrook Health Sciences Centre has made an eHealth initiative, a service called MyChart, available to its patients. MyChart is also known as the Continuity of Care Record system and it streamlines the way health record information is delivered and exchanged between healthcare providers and patients in the hospital saving a lot of time which was earlier wasted in inquiring about a patient's history about disease and medication etc done so far. It helps doctor spend some quality time with patient and making the most of it. Also, it minimizes time wastage and further reducing waiting time.

With many advantages, EHRs come with their own set of disadvantages such as finance issues, changes in work flow. Also, information privacy and security concern is a big disadvantage in incorporating an EHR.

\section{CONCLUSION}

It is quite known that in some way or the other, patients are dealing with the problem of waiting in a queue. There are different issues in all medical care units at several levels namely, Appointment systems, progressive Patient flow, Patient records, Examination procedures which lead to increased waiting time at each level leaving patients highly dissatisfied and delayed medical care. Hospitals are trying to tackle this shortfall in daily hospital activities, taking help of techniques such as queuing models, process models, Hospital Information System, Six Sigma, Simulations. However, issues like lack of co-ordination between hospital interfaces, waiting time of patients queuing for special treatments and many 


\section{International Journal of Engineering Applied Sciences and Technology, 2019 \\ Vol. 4, Issue 1, ISSN No. 2455-2143, Pages 14-23 \\ Published Online May 2019 in IJEAST (http://www.ijeast.com)}

more, which must also be explored in future researches, along with studying the impact of emergency cases more extensively.

\section{REFERENCE}

[1] Dansky K.H, Miles J.. Patient Satisfaction with Ambulatory Health Care Services; Waiting Time and Filling Time. Hospital Service Adm, 1997; 42: 165-177

[2a] Vissers, J. H. (1998). Health care management modelling: a process perspective. Health Care Management Science, 1(2), (pp. 77-85)

[2b] Adeleke RA, Ogunwale O.D., Halid O.Y.(2009). Application of Queuing Theory to Waiting Time of OutPatients in Hospitals The Pacific Journal of Science and Technology Volume 10. No. 2. Nov. 2009

[3] Mardiah F P, Basri M H, The Analysis of Appointment System to Reduce Outpatient Waiting Time at Indonesia's Public Hospital, Human Resource Management Research, Vol. 3 No. 1, 2013, pp. 27-33. doi: 10.5923/j.hrmr.20130301.06.

[4] Parasuraman, A Parsu \& Zeithaml, Valarie \& Berry, Leonard. (1985). A Conceptual Model of Service Quality and its Implication for Future Research (SERVQUAL). The Journal of Marketing. 49. 41-50. 10.2307/1251430.

[5] Dinesh T.A, Singh S., Nair P, Remya T R(2013) Reducing Waiting Time In Outpatient Services Of Large University Teaching Services Of Large University Hospital -- A Six Sigma Approach, Management in health XVII/1/2013; (pp. 31-37)

[6] Leddy KM, Kaldenberg DO, Becker BW.(2003) Timelines in ambulatory care treatment: An examination of patient satisfaction and wait times in medical practices and outpatient test and treatment facilities. J Ambulatory Care Manage. 26:138-149.

[7] Sharif JHM, Sukeri S. Study on waiting time at the paediatric dental clinic, Kuala Lumpur Hospital. Journal of Quality Improvement. 2003;7(1):19-23

[8] Johannessen, K. A., \& Alexandersen, N. (2018). Improving accessibility for outpatients in specialist clinics: reducing long waiting times and waiting lists with a simple analytic approach. BMC health services research, 18(1), 827. doi:10.1186/s12913-018-3635-3

[9] Lindsay P, Schull M, Bronskill S, et al. The development of indicators to measure the quality of clinical care in emergency departments following a modified-Delphi approach. Acad Emerg Med.2002;9:1131-1139. doi: 10.1111/j.1553-2712.2002.tb01567.x

[10] Maritz, D., Hodkinson, P., \& Wallis, L. (2010). Identification of performance indicators for emergency centres in South Africa: results of a Delphi study. International journal of emergency medicine, 3(4), 341-349. doi:10.1007/s12245010-0240-6
[11] Ernst \& Young, Health barometer 2010: Survey on the quality of health care in Germany. Technical report, (2011) (in German)

[12] Boudreaux ED, d'Autremont S, Wood K, Jones GN. Predictors of emergency department patient satisfaction: stability over 17 months. Academic emergency medicine. 2004;11(1):51-

58.http://dx.doi.org/10.1197/j.aem.2003.1106.1012.

[13] Pandit, A. \& Kulkarni, M. (2018). To Study the Emergency Department Patient Process Flow in Hospital.Indian Journal of Public Health Research \& Development, July-September 2017, Vol. 8, No. 3(pp.286290)

[14] Vikas Bajpai, "The Challenges Confronting Public Hospitals in India, Their Origins, and Possible Solutions," Advances in Public Health, vol. 2014, Article ID 898502, 27 pages, 2014. https://doi.org/10.1155/2014/898502. [15] Vargas, I., Mogollón-Pérez, A. S., De Paepe, P., Ferreira da Silva, M. R., Unger, J. P., \& Vázquez, M. L., (2016), Barriers to healthcare coordination in market-based and decentralized public health systems: a qualitative study in healthcare networks of Colombia and Brazil. Health policy and planning, 31(6), (pp. 736-748). Doi:10.1093/heapol/czv126

[16] Koo, Pyung-Hoi \& Jang, Jaejin \& Nielsen, Karl \& Kolker, Alexander. (2010). Simulation-based patient flow analysis in an endoscopy unit. 2010 IEEE Workshop on Health Care Management, WHCM 2010. 1-6. 10.1109/WHCM.2010.5441266.

[17] Melo T. (2012) A note on challenges and opportunities for Operations Research in hospital logistics. Technical reports on Logistics of the Saarland Business School, Ideas.

[18] https://www.genpact.com/docs/resource-/intelligentprocess-at-work-genpact-helps-miami-childrens-hospitaldeliver-a-superior-patient-experience

[19] Brahimi, M., \& Worthington, D. J.(1991). Queuing models for out-patient appointment systems - a case study. The Journal of Operational Research Society, 42, (pp. 733746).

[20] Yeon, N., Taesik Lee \& Hoon Jang (2010) : Outpatient Appointment Scheduling with Multi-Doctor sharing Resources. Proceedings of the 2010 Winter Simulation Conference Report 2 (2012)

[21] Aghazadeh S., Aliyev A., and Ebrahimnezhad M., (2012), Review the Role of Hospital Information Systems in Medical Services Development. International Journal of Computer Theory and Engineering, Vol. 4, No. 6.

[22] Choudhury NR, "Framework for development of Information Technology Infrastructure for Health (ITIH) care in India - a critical study", Qualitative and Quantitative Methods in Libraries, Vol 5 No 4 (2016): December 2016.

[23] Melo, T. (2012). Hospital logistics: Lessons learned from using Operations Research to improve resource management. [24] Fiems, D., Koole, G. and Nain, P. (2007) Waiting times of scheduled patients in the presence of emergency requests. 


\section{International Journal of Engineering Applied Sciences and Technology, 2019 \\ Vol. 4, Issue 1, ISSN No. 2455-2143, Pages 14-23 \\ Published Online May 2019 in IJEAST (http://www.ijeast.com)}

http://www.math.vu.nl/ koole/articles/report05a/art.pdf, accessed August 6, 2007.

[25] Fiems D, Koole G and Nain P. (2005) Waiting times of scheduled patients in the presence of emergency requests, http://www.math.vu.nl/ koole/publications/2005report1/art.pd $\underline{f}$

[26] Koeleman P, Koole G. (2012). Optimal outpatient appointment scheduling with emergency arrivals and general service times.

[27] Chowdhury, M. S. R., Rahman, M. T., \& Kabir, M. R. (2013). Solving of waiting lines models in the bank using queuing theory model the practice case: Islami bank bangladesh limited, chawk bazar branch, chittagong. IOSR Journal of Business And Management, 10, pp-22-29. https://doi.org/10.9790/487X-1012229.

[28] Ozturk, O., Di Mascolo, M., Espinouse, M.-L., \& Gouin, A. (2010). Minimizing the sum of job completion times for washing operations in hospital sterilization services. Paper presented at the 8th International Conference of Modeling and Simulation (MOSIM'10).

[29] Helbig, M., Helbig, S., Knecht, R., Kahla-Witzsch, H., \& Gstöttner, W. (2007). Quality management: reduced waiting time and enhanced efficiency in a university ear, nose, and throat outpatient department. HNO, 55(1), 29.

[30] Edwards T. and Suresh S., Applications of Agents in Hospital Search and Appointment System, International Journal of E-services and Mobile Applications, vol. 3, no. 4, (pp. 57-81).

[31] Hylton A. III and Sankaranarayanan S. Application of Intelligent Agents in Hospital Appointment Scheduling System, International Journal of Computer Theory and Engineering, Vol. 4, No. 4, August 2012

[32] Wenjun Cao, Yi Wan, Haibo Tu, Fujun Shang, Danhong Liu, Zhijun Tan,Caihong Sun, Qing Ye, Yongyong Xu.(2011)• A web-based appointment system to reduce waiting for outpatients: A retrospective study, BMC Health Services Research 2011

[33] Jachson Jr, (1957).Networks of Waiting Lines, Operations Research, Vol.5, (pp. 518-521)

[34] Afrane S , Appah A (2014), Queuing theory and the management of Waiting-time in Hospitals: The case of Anglo Gold Ashanti Hospital in Ghana. International Journal of Academic Research in Business and Social Sciences February 2014, Vol. 4, No. 2 ISSN: 2222-6990.

[35] Taylor, A. (2006). Electronic visit in East Kent Hospitals NHS. Journal of medical sciences, 11.

[36] Mohebbifar R, Hasanpoor E, Mohseni M, Sokhanvar M, Khosravizadeh O, Isfahani HM (2013). Outpatient Waiting Time in Health Services and Teaching Hospitals: A Case Study in Iran, Global Journal of Health Science, Nov 2013.

[37]

(http://www.unitypoint.org/cedarrapids/filesimages/Medical\% 20Staff/MAYO/Talking\%20Points.pdf) [38]http://www.theglobeandmail.com/report-onbusiness/small-business/starting-out/virtual-checkupvancouver-startup-connects-doctors-patients-through-videochat/article12445957/

[39] Willcox, S., Seddon, M., Dunn, S., Edwards, R. T., Pearse, J., \& Tu, J. V. (2007). Measuring and reducing waiting times: a cross-national comparison of strategies. Health Affairs, 26(4), (pp.1078-1087).

[40] Čiarnienè, R., Vienažindienè, M. (2012). Lean manufacturing: theory and practice. Economics and management, $\quad 17, \quad$ (pp $132-738$ ). Doi:10.5755/j01.em.17.2.2205

[41] Najib S, Yusop N, Ali H, Using Simulation To Reduce Out-Patient Waiting Time: A Case Study At Jitra Health Center. Faculty of Management of Technology, Keda

[42] Aeenparast A, Tabibi SJ, Shahanaghi K, Aryanejhad MB, (2013). Reducing Outpatient Waiting Time: A Simulation Modeling Approach, Iranian Red Crescent Medical Journal. 15(9). 